\title{
Fotografia, Patrimônio e Mundialização da Cultura: um relato de experiência da exposição "Barco de Fogo"
}

\author{
Fotografía, Patrimonio y Mundialización de la Cultura: um relato de \\ experiencia de la exposición "Barco de Fogo"
}

\author{
Photography, Heritage and Globalization of Culture: an experience report \\ of the exhibition "Barco de Fogo"
}

\author{
Dra. Rosana Eduardo da Silva Leal ${ }^{1}$
}

\begin{abstract}
Resumo
As exposições fotográficas constituem importantes ferramentas de difusão artística, educativa e cultural. Quando realizadas no exterior, atuam como mecanismos de promoção e mundialização das culturas, servindo como instrumentos importantes de valorização do patrimônio e das identidades de povos e sociedades. É nesta vertente que se situa o presente trabalho, que tem por objetivo analisar a relação entre fotografia, patrimônio e mundialização da cultura, por meio da exposição fotográfica "Barco de Fogo", do artista sergipano Márcio Garcez. O barco de fogo constitui uma das manifestações culturais mais significativas do estado de Sergipe, fazendo parte do ciclo junino do estado. Sua produção envolve um considerado número de pessoas presentes desde o processo de confecção, passando pela soltura e chegando à apresentação. Sua confecção se dá nos barracões existentes no município, estando embasada em um trabalho coletivo que está associado a uma mistura de carpintaria, engenharia e artesanato. Tal manifestação cultural resulta de um saber-fazer construído por meio de sensibilidade, criatividade e engenhosidade de seus artesãos, conhecidos como fogueteiros. Para refletir sobre tais temas, trataremos do papel da fotografia como registro documental, etnográfico e histórico, considerando sua importância como fonte de pesquisa sobre o patrimônio dos povos e comportamentos culturais. Posteriormente apresentaremos a cultura dos barcos de fogo, tema principal da exposição aqui apresentada, bem como seu autor. E em seguida, trataremos das edições da referida mostra artística.
\end{abstract}

Palavras-chave: Exposições; fotografia; patrimônio; mundialização, cultura.

\section{Resumen}

Las exposiciones fotográficas constituyen importantes herramientas de difusión artística, educativa y cultural. Cuando se realizan en el exterior, actúan como mecanismos de promoción y mundialización de las culturas, sirviendo como instrumentos importantes de valorización del patrimonio y de las identidades de pueblos y sociedades. En esta vertiente se sitúa el presente trabajo, que tiene por objetivo analizar la relación entre fotografía, patrimonio y mundialización de la cultura, por medio de la exposición fotográfica "Barco de Fogo", del artista sergipano Márcio Garcez. El "barco de fogo" constituye una de las manifestaciones culturales más significativas del estado de Sergipe, formando parte del ciclo junino del estado. Su producción involucra a un considerado número de personas presentes desde el proceso de confección, pasando por la soltura y llegando a la presentación. Su confección se da en los barracones existentes en el municipio, estando basada en un trabajo colectivo que está asociado a una mezcla de carpintería, ingeniería y artesanía. Tal manifestación cultural resulta de un saber hacer construido por medio de sensibilidad, creatividad e ingeniosidad de sus artesanos, conocidos como "fogueteiros". Para reflexionar sobre tales temas, trataremos del papel de la fotografia como

\footnotetext{
${ }^{1}$ Doutora em Antropologia pela Universidade Federal de Pernambuco; Coordenadora do Grupo de Pesquisa em Antropologia e Turismo; Docente do Departamento de Turismo da Universidade Federal de Sergipe; Brasil; e-mail: rosanaeduardo@yahoo.com.br. Trabalho apresentado no I Seminário Latino-Americano de Estudos em Cultura - SEMLACult, Foz do Iguaçu/PR, Brasil, 2017.
} 
registro documental, etnográfico e histórico, considerando su importancia como fuente de investigación sobre el patrimonio de los pueblos y comportamientos culturales. A continuación presentaremos la cultura de los barcos de fuego, tema principal de la exposición aquí presentada, así como su autor. Posteriormente trataremos de las ediciones de dicha muestra artística.

Palabras clave: Exposiciones; fotografia; patrimonio; cultura de la globalización.

\begin{abstract}
Photographic exhibitions are important tools for artistic, educational and cultural diffusion. When carried out abroad, they act as mechanisms for the promotion and globalization of cultures, serving as important tools for valuing the heritage and the identities of peoples and societies. It is in this strand that the present work is located, whose objective is to analyze the relationship between photography, heritage and the globalization of culture, through the photographic exhibition "Barco de Fogo", by the Sergipe artist Márcio Garcez. The "barco de fogo" constitutes one of the most significant cultural manifestations of the state of Sergipe, being part of the junino cycle of the state. Its production involves a considered number of people present from the process of making, passing by the release and arriving at the presentation. Its confection takes place in the existing barracks in the municipality, being based on a collective work that is associated to a mixture of carpentry, engineering and crafts. Such cultural manifestation results from a know-how built through the sensitivity, creativity and ingenuity of its artisans, known as "fogueteiros". To reflect on such themes, we will deal with the role of photography as a documentary, ethnographic and historical record, considering its importance as a source of research on the heritage of peoples and cultural behaviors. Later we will present the culture of the "barcos de fogo", main theme of the exhibition presented here, as well as its author. And then, we will deal with the editions of this artistic exhibition.
\end{abstract}

Keywords: Exhibitions; photography; patrimony; Globalization, culture.

\title{
1. Introdução
}

O presente artigo busca refletir sobre a relação entre patrimônio, fotografia e difusão cultural, tendo como objeto de estudo a exposição "Barco de Fogo" realizada nas cidades de Recife, Salamanca (Espanha), Viena (Áustria), São Paulo e Foz do Iguaçu. Trata-se de uma produção científica vinculada ao Grupo de Pesquisa em Antropologia e Turismo ANTUR/UFS/CNPQ, dentro da linha temática "Identidade e Patrimônio Cultural”.

O acervo é resultado da documentação fotográfica do barco de fogo, uma alegoria pirotécnica ligada ao ciclo junino dos festejos populares, que tem ocorrência exclusiva na cidade de Estância, Sergipe. As imagens fazem parte do registro autoral do fotógrafo Márcio Garcez, que ao longo de mais de vinte anos documenta com experiência, sensibilidade e técnica a cultura popular brasileira.

A exposição conta com trinta e duas imagens, refletindo os detalhes da tradição do fogo presente no município de Estância em Sergipe. 
O uso de fogos no contexto festivo das festas juninas de Estância - SE valoriza o espetáculo com as luzes, o brilho e o estampido, enquanto recursos eficazes de celebração. Os aspectos pirotécnicos inserem-se numa dimensão lúdica que envolve brincadeiras, desafios, riscos, medo, espanto e admiração. O ritual de fogos, além de sua dimensão espetacular, cria uma imensa rede de comunicação entre a população local e os turistas, favorecendo a transmissão de valores e o aprendizado de práticas culturais (SILVA, 2015, p.17).

O acervo traduz um saber-fazer passado de geração em geração, que perpassa o cotidiano e as ruas da cidade sergipana. Em sua primeira edição, a exposição foi realizada com a curadoria da Doutora em História da Arte, Ana Virgínia Queiroz e, nas demais edições, com a curadoria da autora deste artigo e da pedagoga e presidente da Sociedade Austro Brasileira de Educação e Cultura - PAPAGAIO, Vanessa Noronha Tölle.

Para a escrita do artigo, partimos do pressuposto de que o patrimônio se converte em um relevante agente de relações internacionais, na medida em que possibilita o intercâmbio cultural, dando visibilidade e reconhecimento de práticas culturais regionais, muitas vezes desconhecidas fora do país de origem.

O intercâmbio cultural, na medida em que possibilita a transferência de um povo a outro de experiências, ideias e patrimônios valiosos, prolonga, enraíza, consolida e preserva uma atmosfera que favorece o entendimento. Além de contribuir para minimizar julgamentos por estereótipos, esse processo de transferências em geral reforça sentimentos pacíficos pela própria ideia da universalidade do patrimônio cultural e artístico (RIBEIRO, 1989, p.34).

Trata-se de uma ferramenta cultural que tem importante relevância para as relações internacionais entre nações, uma vez que, "a cultura brasileira, ou as culturas brasileiras, podem e devem, assim, constituir matéria-prima para a aceleração de nossos processos de aproximação bilateral, regional e internacional com outros povos e seus governos", conforme salienta Ribeiro (1989, p.26). Entretanto,

[...] torna-se necessário iniciar um esforço de integração entre os diversos (e muitas vezes isolados) segmentos da sociedade brasileira que se dedicam a viver mais intimamente a cultura brasileira: intelectuais, artistas, produtores, professores, críticos, divulgadores e funcionários da administração pública (RIBEIRO, 1989, p. $32)$.

Neste artigo trataremos inicialmente do papel da fotografia como registro documental, etnográfico e histórico, considerando sua importância como fonte de pesquisa sobre o patrimônio dos povos e comportamentos culturais. Em seguida apresentaremos a cultura dos barcos de fogo, tema principal da exposição aqui apresentada, bem como seu autor, o fotógrafo Márcio Garcez. Posteriormente trataremos das edições da referida mostra artística. 


\section{Patrimônio Cultural e Documentação Fotográfica}

O patrimônio cultural brasileiro é formado pela herança de natureza material e imaterial que traz referência à identidade e à memória da sociedade brasileira, através das suas múltiplas expressões artísticas. Desse modo, reúne um conjunto de bens, conhecimentos e realizações historicamente herdados pelos povos que aqui estiveram, que cria identidade e reconhecimento nacional, bem como confere traços de individualidade em relação a outro povo.

Ao ser antropologizado, a nova concepção de patrimônio absorve o simbólico, o imaterial, as festas, a culinária, a religiosidade, as referências étnicas, os saberes, fazeres e técnicas de minorias sociais anteriormente não consideradas. Trata-se do "patrimônio que não mais é visto como excepcionalidade da erudição, mas que, sem deixar de ser isto, passa a ser visto também como o registro do comum, como memória da expressão cultural do homem comum e de sua vida corriqueira" (CERQUEIRA, 2005, p.107).

No Brasil, o registro fotográfico representa um importante instrumento de salvaguarda do patrimônio cultural, valorização e difusão da identidade, história e memória de indivíduos e grupos, bem como dos saberes, crenças, usos e costumes brasileiros. Isso porque, a documentação fotográfica representa um relevante mecanismo de registro de um povo, podendo ser acionada como ferramenta de cidadania por meio de ações educacionais, políticas e culturais capazes de promover a inclusão social, os direitos humanos e o fortalecimento identitário.

Conforme salienta o Programa Nacional do Patrimônio Imaterial, concretizado por meio do Decreto $n^{\circ}$ 3.551, de 04 de agosto de 2000 (BRASIL, 2000), é de fundamental importância à sistematização de informações sobre o patrimônio imaterial registrado, seja em âmbito municipal, estadual ou nacional. Tal documentação deve ocorrer por meio de levantamentos, inventários, mapeamentos, bem como produção de acervos documentais, fotográficos, audiovisuais e etnográficos, que deverão ser disponibilizados para a sociedade e setores interessados. Por isso, a pesquisa, a documentação e divulgação dos bens culturais imateriais são essenciais para dar base às políticas públicas que visem preservar, divulgar e promover a inclusão social dos indivíduos e grupos, que mantém a vitalidade cultural destes bens. Neste âmbito, concordamos com Novaes $(1998$, p. 116) quando salienta que "não é mais aceitável a 
ideia de se relegar a imagem a segundo plano nas análises dos fenômenos sociais e culturais”, pois trata-se de um recurso que poderá servir como mecanismo de valorização da tradição e de seus mantenedores, tendo em vista o desenvolvimento social, cultural, econômico e turístico das localidades.

"A fotografia foi um dos inventos da modernidade que revolucionou a forma do homem se representar e se relacionar" (BONI; MORESCHI, 2007, p. 142). Esta ferramenta atua como recurso de difusão cultural, proporcionado o intercâmbio entre povos e nações. Possibilita ainda múltiplas maneiras de compartilhar a cultura com o outro, afetando e deixando-se afetar.

\begin{abstract}
A história das culturas passou a desfrutar de novas dimensões e interpretações com o uso de imagens. Isso contribuiu para a compreensão mais aprofundada do universo simbólico. Na expressão de sistemas e atitudes, por meio dos quais grupos sociais se definem, constroem identidades e apreendem-se mentalidades (BONI; MORESCHI, 2007, p. 154).
\end{abstract}

No diálogo com o patrimônio, a fotografia apresenta-se como um documento de representação social. Na percepção de Sontag (2004, p. 16), “fotos fornecem um testemunho. Algo de que ouvimos falar mas de que duvidamos parece comprovado quando nos mostram uma foto".

As fotografias produzidas, mais do que instrumentos de trabalho, articulavam-se às concepções patrimoniais existentes e, assim, constituíam um olhar específico sobre objetos artísticos, edificações, cidades e paisagens. São, portanto, consideradas parte integrante do patrimônio cultural brasileiro (IPHAN, 2008, p.13-14).

Trata-se de um espelho do cotidiano de uma sociedade, que, conforme salienta Martins (2013), atua como um método de registro da informação social e cultural, que serve como instrumento de investigação estética e científica. Além disso, funciona como um registro e reconstrução da memória social, contribuindo na reconstituição histórica de uma sociedade ${ }^{2}$.

\title{
3. A Cultura dos Barcos de Fogo
}

\footnotetext{
2 "A recepção da imagem pelo espectador depende de uma negociação de sentido que transgride a própria imagem e que se realiza no contexto cultural - e com os textos culturais - com o qual ele convive. A imagem, assim, aponta para esses textos e pode, inclusive, ser lida com o mesmo peso de um texto" (BONI; MORESCHI, 2007, p.154).
} 
O barco de fogo constitui uma das manifestações culturais mais significativas do estado. Sua produção envolve um considerado número de pessoas presentes desde o processo de confecção, passando pela soltura e chegando à apresentação. Sua confecção se dá nos barracões existentes no município, estando embasada em um trabalho coletivo que está associado a uma mistura de carpintaria, engenharia e artesanato. Tal manifestação cultural resulta de um saber-fazer construído por meio de sensibilidade, criatividade e engenhosidade de seus artesãos, conhecidos como fogueteiros e barqueiros.

Elemento importante dos festejos juninos da cidade de Estância e do estado de Sergipe, o Barco de fogo teve sua origem ainda nos idos do fim da década de 1930, criado pelas mãos do jardineiro e fogueteiro, Francisco da Silva Cardoso (19071971), mais popularmente conhecido como 'Chico Surdo', por decorrência de perda de audição. Ele concebeu o barco a partir de uma espada que correu ao longo de um fio de arame e que aperfeiçoando levou ao atual barco que conhecemos hoje. $\mathrm{O}$ barco de fogo, juntamente com o ritual do Pisa-Pólvora e as tradicionais guerras de buscapés, é uma das (se não a maior) expressões do São João estanciano ${ }^{3}$.

Com a entrada do mês de junho, os barcos de fogo tomam conta das ruas do município de Estância, tendo como plateia os moradores e visitantes que durante várias noites assistem ao espetáculo de luz, cor e som que envolve tal manifestação cultural.

[...] O barco de fogo é um artefato cultural feito de madeira e papel colorido, com quatro fogos de espada, em formato de barco. Pendurado em um arame, previamente encaixado por duas forquilhas, montadas de um determinado ponto de uma rua ao outro extremo em linha reta. $\mathrm{O}$ barco de fogo percorre o arame ao serem acesas as espadas, estas impulsionam o barco e fazem-no correr pela extensão do arame, deixando um rastro luminoso. Ele é um fogo de artifício feito para ser apreciado nas apresentações de corridas e nos concursos públicos. Além de ser o ícone representativo dos festejos juninos da cidade, divulgada pelo slogan 'Estância, a capital brasileira do barco de fogo' (SILVA, 2016, p.03).

Trata-se de uma tradição que representa um elemento distintivo e exclusivo do ciclo junino da cidade de Estância, constituindo-se como importante elemento de identidade local. Atualmente o barco de fogo é considerado Patrimônio Cultural Imaterial do Estado de Sergipe através do Conselho Estadual de Cultura.

Muito recorrente no território sergipano, o bambu é a base para a confecção dos artefatos da cultura do fogo (espadas, busca-pés e barcos de fogo) em Estância. Sua retirada começa a partir do mês de dezembro, na fase da lua cheia, como indica a tradição, por se tratar de um período

\footnotetext{
3 SOUZA, M.S. O Barco de Fogo como Patrimônio Imaterial: subsídios para o registro. Disponível em: http://www.ufs.br/conteudo/2294. Acesso em 20.jul.2017.
} 
ideal para minimizar a incidência de pragas que podem comprometer a qualidade dos gomos. Após a retirada, os bambus são levados aos barracões onde são expostos ao sol, passando por um período de secagem.

Após secarem ao sol, os bambus são serrados e cortados em gomos, recebendo a denominação de tabocas. Estas são lixadas em suas extremidades e depois levadas ao fogo com inseticida para retirada das pragas. O procedimento de cozimento também evita o apodrecimento das peças, bem como o futuro aparecimento de bichos que podem danificar a estrutura do artefato. Posteriormente são levadas ao sol e, quando já estão secas, são enroladas com cordão de algodão ou sisal, garantindo maior resistência. Depois as tabocas são preenchidas alternadamente por camadas de barro e pólvora (SILVA, 2015).

O teste da pólvora envolve uma etapa que requer experiência, prudência e percepção. Durante os testes, os fogueteiros observam o processo de queima e velocidade da pólvora. Depois desta etapa, o material é utilizado no preenchimento dos busca-pés, espadas e demais fogos de artifício que serão comercializados e utilizados durante os festejos juninos.

A pólvora é o alimento da cultura do fogo em Estância.

A fabricação dos fogos é uma aprendizagem cultural. As crianças aprendem observando seus pais, avós, tios e amigos, tanto ao fabricá-los quanto ao soltá-los. É comum encontrar no mês de junho, no espaço do forródromo, crianças brincando de fazer fogo. Elas se reúnem para fazer fogo de pitu, pequena bomba que provoca muito barulho ao explodir. E assim vão brincando e testando: fazem o fogo, soltam, percebem a diferença quanto à duração da explosão e ao barulho provocado (SILVA, 2015, p.15).

Tempos atrás, os preparativos envolviam amigos, vizinhos e familiares em torno do ritual do "pisa pólvora". Entretanto, nos dias atuais, tal procedimento é feito em barracões distantes da cidade, por medida de segurança e proteção. São nestes espaços que os mestres do fogo realizam a manipulação, o teste e o armazenamento deste material. Os fogueteiros se reúnem em torno do pilão, num procedimento que envolve trabalho artesanal e coletivo.

\section{Arte, Técnica e Sensibilidade}

Márcio José Garcez Vieira (Márcio Garcez) nasceu em Aracaju, Sergipe (Brasil). É graduado em Comunicação Social pela Universidade Federal de Sergipe e possui mais de vinte anos de experiência profissional, tendo sido agraciado com mais de quinze prêmios no âmbito da 
fotografia. Atuou como Consultor da Secretaria dos Direitos Humanos da Presidência da República em Brasília e foi premiado no $4^{\circ}$ Salão de Fotografia de Aracaju.

Participou de três edições do Festival Cultural do Brasil em Viena - Áustria e do Salão Internacional de Arte Contemporânea no Carrousel du Louvre em Paris, com fotografias publicadas no Guide Biennal d'Art Contemporain - 2014/2015. Publicou fotos em catálogos de exposições como "Barco de Fogo por Márcio Garcez" (2014); "Manifestações Culturais Sergipanas (2014); livro "Um Sentir sobre as Artes Visuais em Sergipe (2013); catálogo "Lambe- Sujo X Caboclinho" (2012); livro "Do Litoral ao Sertão" (2010); catálogo do artista plástico "Leonardo Alencar" (2006) e livro "Senhor dos Passos em Todos os Passos" (2005). Possui fotos publicadas em diversas revistas da Editora Abril (São Paulo); Folha de São Paulo (São Paulo); Companhia das Letras (São Paulo); Editora Trip (São Paulo); Jornal Valor Econômico (São Paulo); Isto é Gente; Editora Saraiva; Ática; Época; Jornal Zero Hora e Correio Brasiliense.

O trabalho de Márcio Garcez transita entre a arte, a técnica e a sensibilidade. Sua identidade artística revela-se na inquietude de registrar o cotidiano humano e suas produções culturais, compartilhando com o público a beleza e a profundidade do quase imperceptível. Em todo o tempo de atuação profissional, o fotógrafo tem registrado a alma, as cores e as texturas da cultura popular brasileira. Na exposição Barco de Fogo, o artista evidencia seu olhar etnográfico sobre a referida manifestação cultural, apresentando a engenhosidade de seus artesãos.

O trabalho de Márcio Garcez segue a linha da fotografia etnográfica, recurso utilizado como fonte documental para registro de povos, culturas e sociedades, estando embasada em uma Antropologia Visual.

\footnotetext{
A fotografia etnográfica pode estar inserida em trabalhos científicos, exposições ou diversos tipos de publicação. Pode ser caracterizada como objeto de estudo, pesquisa ou como mera ilustração. Esse tipo de trabalho contribui para que haja um resgate de informações relacionadas aos diferentes tipos de etnias. Além disso, compila dados de conhecimento, que podem servir como fonte de comparação anacrônica, posto que a cultura e os costumes das etnias estão sujeitos a transformações (BONI, MORESCHI, 2007, p.139).
}

Márcio Garcez registrou os bastidores da cultura do fogo em Estância/Sergipe, revelando os processos de feitura, espaços de produção e apresentação, bem como a matéria-prima, o trabalho e as técnicas de seus produtores. Pelas lentes do referido fotógrafo, que atua como 
um etnógrafo visual, é possível conhecer os fogueteiros, visitar os barracões e entender a complexidade da tradicional confecção dos fogos de artifício, convidando o público visitante a contemplar as luzes e cores das corridas de barcos de fogo, possibilitando conhecer um pouco dos festejos juninos de Sergipe.

\section{As edições da Exposição "Barco de Fogo"}

A documentação fotográfica dos barcos de fogo se deu ao longo de quatro meses, período em que o fotógrafo Márcio Garcez registrou minunciosamente os bastidores da referida manifestação cultural, identificando os processos de criação, espaços de produção, apresentação e fruição, bem como a matéria-prima, o trabalho e as técnicas de seus produtores, revelando a presença desta tradição no cotidiano da cidade de Estância em Sergipe.

Os primeiros delineamentos da exposição ocorreram em 2013 em face do edital do Projeto Expositivo de Fotografia - Sala Alcir Lacerda Convocatória 2013/2014, promovido pelo Governo do Estado de Pernambuco, por meio da SECULT - Secretaria de Cultura do Estado de Pernambuco e FUNDARPE - Fundação do Patrimônio Histórico e Artístico de Pernambuco. O projeto nasceu com a finalidade de apresentar, a partir da narrativa fotográfica, os bastidores da cultura dos barcos de fogo, destacando o trabalho dos fogueteiros, o registro dos barracões, bem como a complexidade da tradicional confecção e soltura dos fogos de artifício. Desde a sua concepção, a finalidade do acervo foi proporcionar a valorização estética, cultural e artística desta tradição, por meio de abordagem etnográfica.

Para possibilitar a divulgação do projeto, foi criada uma página no facebook com o título "Barco de Fogo por Márcio Garcez", que se tornou fundamental no registro audiovisual das edições da exposição. Atualmente a comunidade conta com mais de 600 participantes, tornando-se importante fonte histórica do projeto. A referida página atua como principal ferramenta de comunicação e diálogo com o público, constituindo-se como espaço de divulgação de conteúdos audiovisuais, como fotos, folders, matérias jornalísticas e vídeos. Este ambiente virtual também constitui um espaço de memória do projeto, uma vez que se tem o histórico dos conteúdos de cada edição da mostra. A equipe responsável pelo projeto atua no processo de planejamento e realização da exposição, estando responsável por diversas atividades, como elaboração de textos, produção cultural, curadoria, registro fotográfico, 
pesquisa científica, gerenciamento de página em rede social, clipping, acompanhamento de ações educativas, bem como captação de recurso e participação em editais.

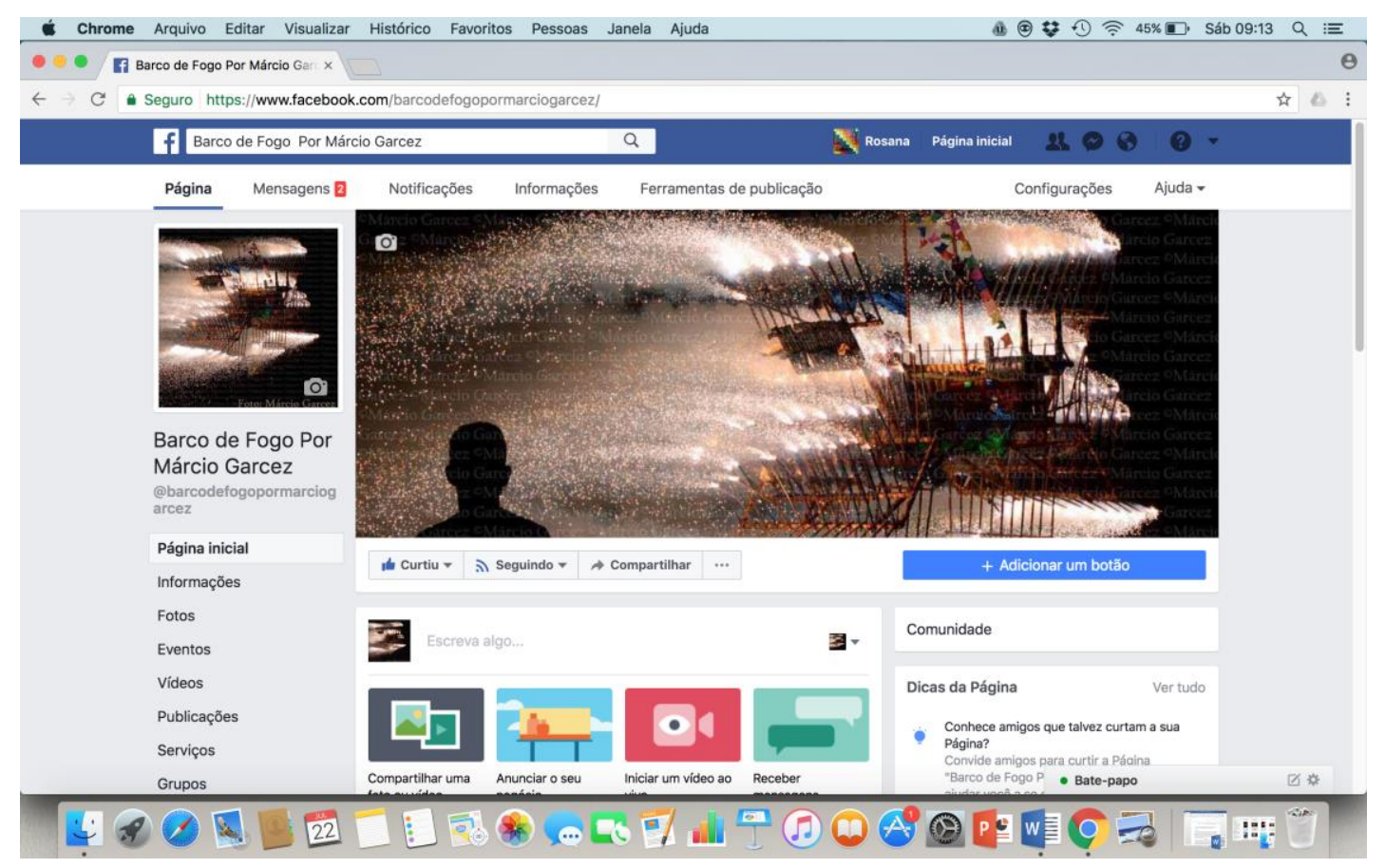

Figura 1 - Página da Exposição em Rede Social Fonte: acervo do projeto

A primeira edição do projeto foi realizada de 21 de setembro a 22 de novembro de 2014 na Torre Malakoff - Recife Antigo, em cumprimento às exigências do edital do Projeto Expositivo de Fotografia - Sala Alcir Lacerda Convocatória 2013/2014, promovido pelo Governo do Estado de Pernambuco, por meio da SECULT - Secretaria de Cultura do Estado de Pernambuco e FUNDARPE - Fundação do Patrimônio Histórico e Artístico de Pernambuco. A exposição contou com um público diversificado, abarcando estudantes, turistas e moradores do estado. Entretanto, teve como principal público os estudantes provenientes de instituições de ensino do estado. Segundo o relatório do Educativo Torre Malakoff, a mostra recebeu 32 grupos com este perfil, totalizando 1606 professores e estudantes de escolas municipais, estaduais e particulares da Região Metropolitana do Recife, bem como de outras regiões e municípios do estado, abarcando também institutos técnicos e universidades. 
RELACult - Revista Latino-Americana de Estudos em Cultura e Sociedade

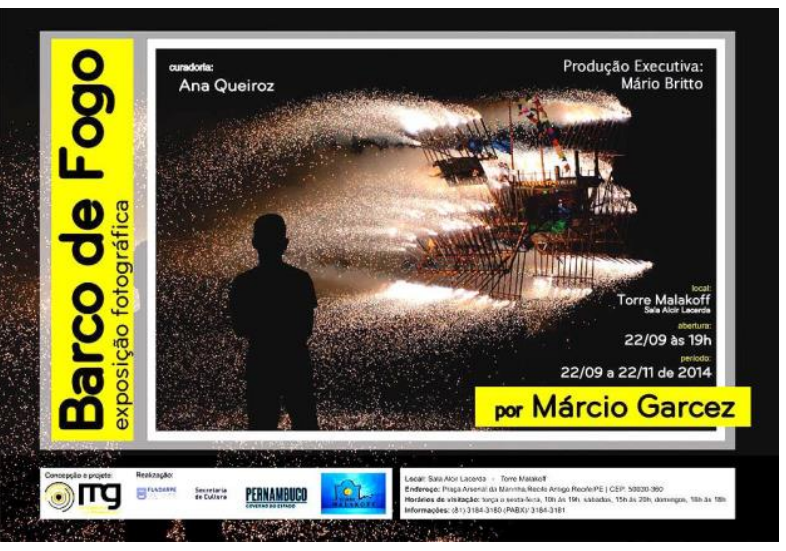

Figura 02 - Convite da Exposição em Recife Fonte: acervo do projeto

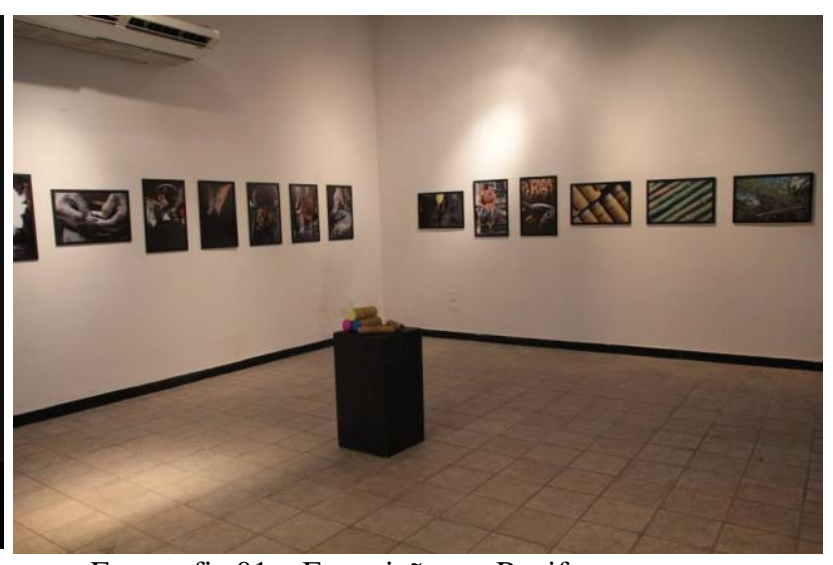

Fotografia 01 - Exposição em Recife

Fonte: acervo do projeto

A segunda edição do projeto ocorreu na Espanha, como resultado da aprovação na Convocatória para Residência Artística 2015 do Centro de Estudios Brasileños - CEB, da Universidad de Salamanca. A exposição foi inaugurada no dia 17 de junho, na Sala de Exposiciones Palacio de Maldonado do Centro de Estudios Brasileños e ficou aberta à visitação até o dia 31 de julho de 2015. A mostra foi visitada por autoridades locais, pesquisadores, estudantes brasileiros e estrangeiros, críticos de arte, jornalistas, moradores, bem como professores e turistas das mais distintas nacionalidades. A exposição foi amplamente divulgada na imprensa local, fazendo parte de diversas atividades realizadas pelo Centro de Estudios Brasileños.

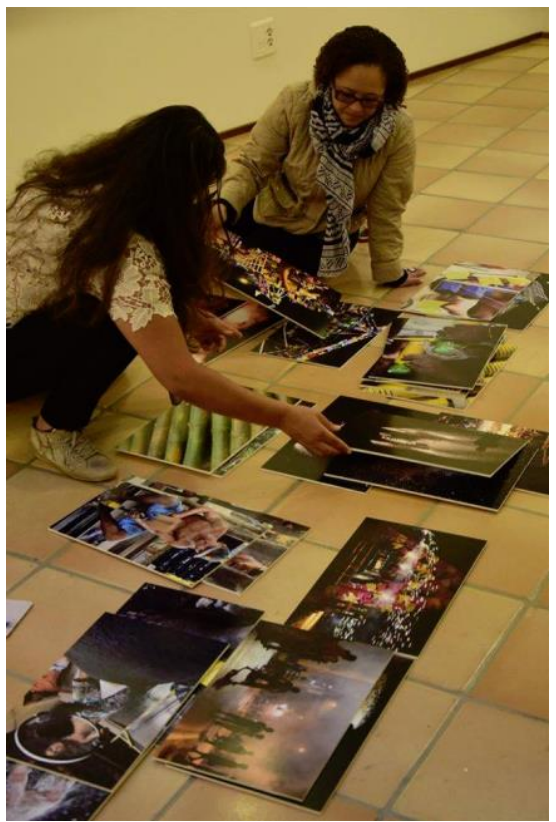

Fotografia 02 - Curadoria Fonte: Acervo do projeto.

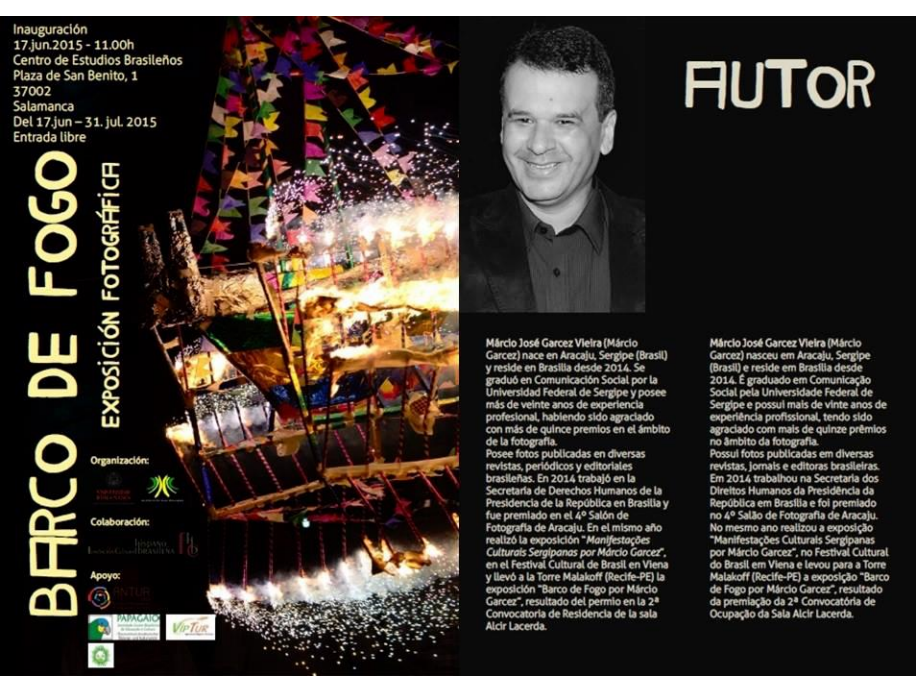

Figura 03 - Convite da exposição em Sala $1 \quad$ o: Fonte: Centro de Estudios Brasileños 


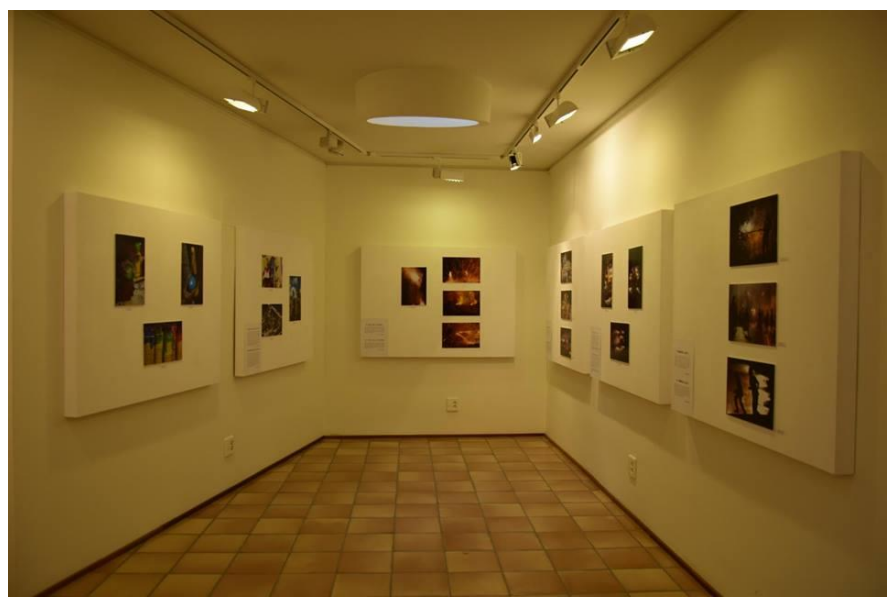

Fotografia 03 - Espaço expositivo do Centro de Estudios Brasileños, Espanha Fonte: acervo do projeto

Após a temporada na Espanha, a exposição seguiu para sua terceira edição, que aconteceu na Áustria como parte da programação do Festival do Brasil em Viena 2015 (Brasilianisches Kulturfestival Wien 2015), que ocorreu nos dias 29, 30 e 31 de outubro. O evento, que contou com uma intensa programação artístico-cultural, foi uma iniciativa da Sociedade Austro Brasileira de Educação e Cultura - Papagaio, organização não-governamental sem fins lucrativos. O festival teve por finalidade apresentar e difundir a diversidade cultural brasileira, por meio da arte, da cultura e da educação - três vertentes presentes no trabalho do referido fotógrafo. As imagens da exposição "Barco de Fogo" também se constituíram como a marca visual do evento. A mostra contou com o mesmo acervo exposto em Salamanca/Espanha, que foi cedido temporariamente pelo Centro de Estudios Brasileños. A abertura ocorreu no dia 30 de outubro na Biblioteca do Instituto de Romanística da Universidade de Viena (Universitätsbibliothek Wien - Fachbereichsbibliothek Romanistik) e ficou exposto até o dia 30 de novembro de 2015.

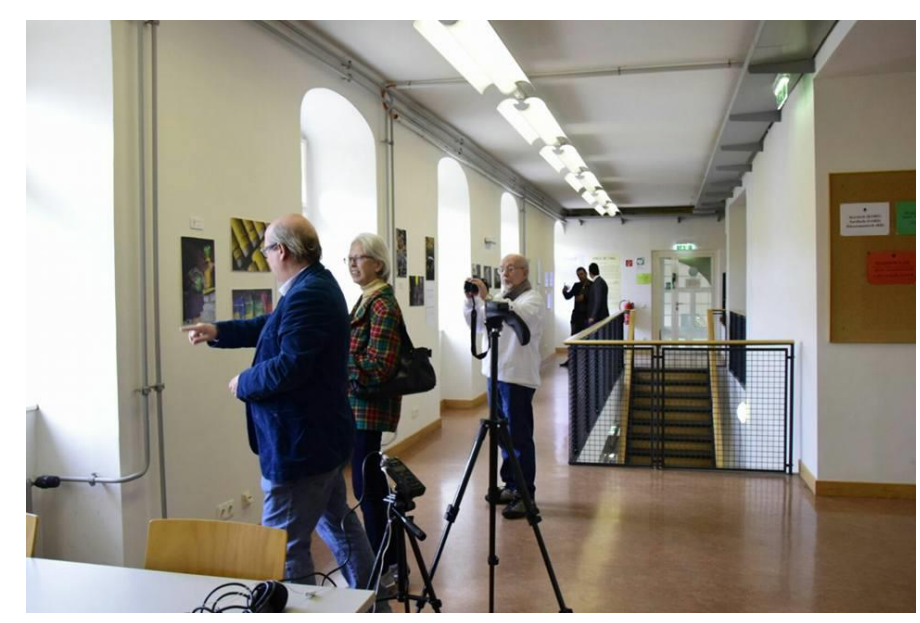




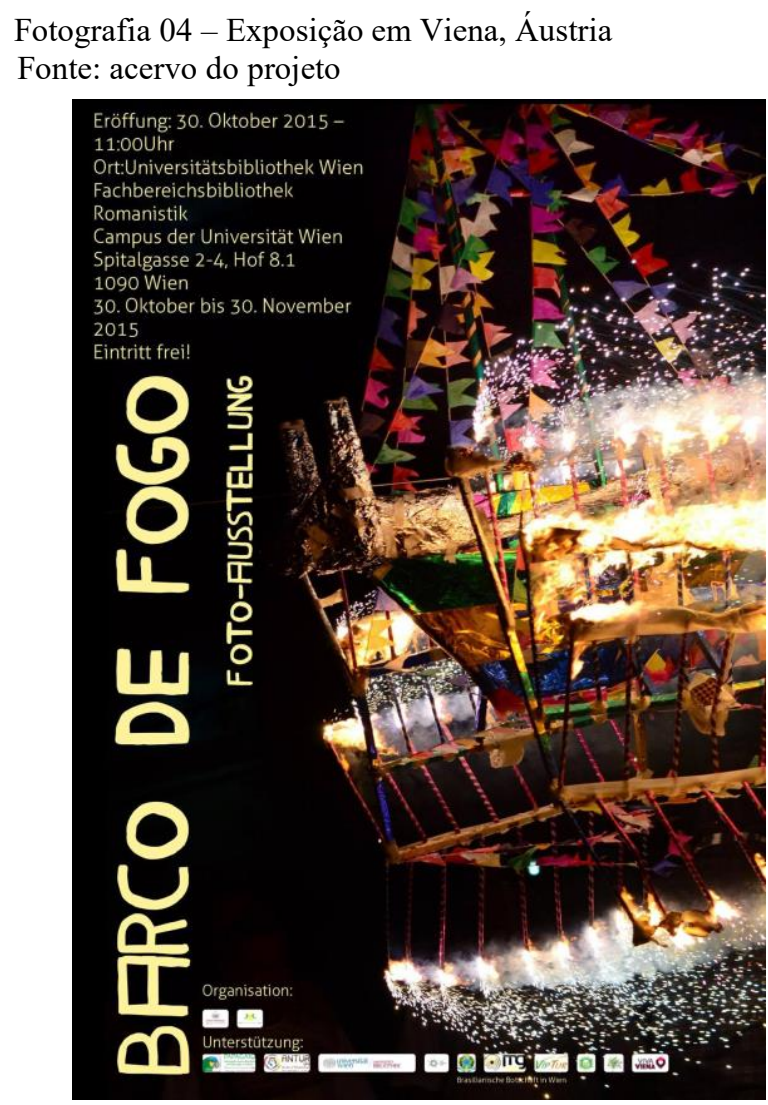

Figura 04 - Convite da Exposição em Viena Fonte: Centro de Estudios Brasileños

Em dezembro de 2015, o acervo foi exposto no Salão da Fotografia Consigo em São Paulo. O espaço é destinado a promover a apreciação e discussão da fotografia enquanto expressão artística, bem como promover os trabalhos de fotógrafos profissionais e amadores, por meio das exposições realizadas. Trata-se de um espaço vinculado à Consigo Cine Foto - loja que se dedica à comercialização de equipamentos e serviços fotográficos para os mais diversos públicos.

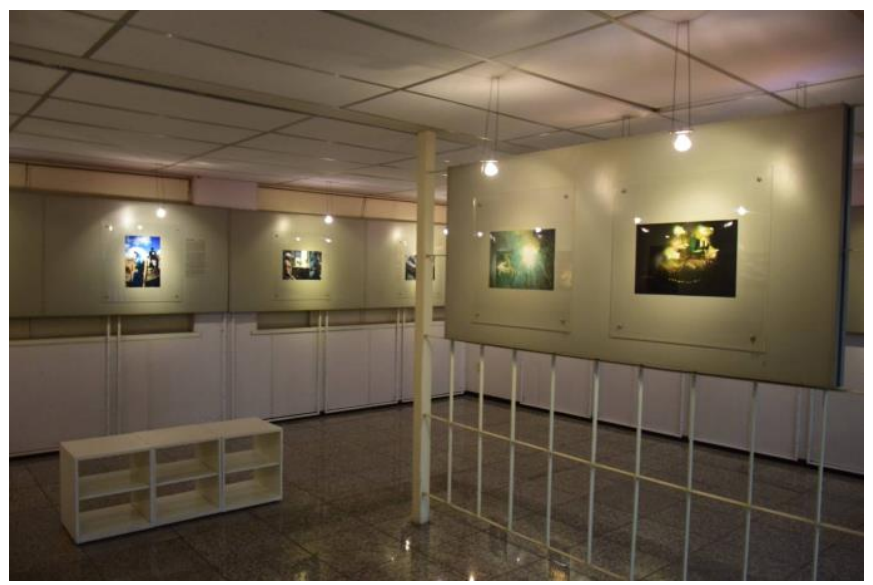


Fotografia 05 - Exposição em São Paulo

Fonte: acervo do projeto

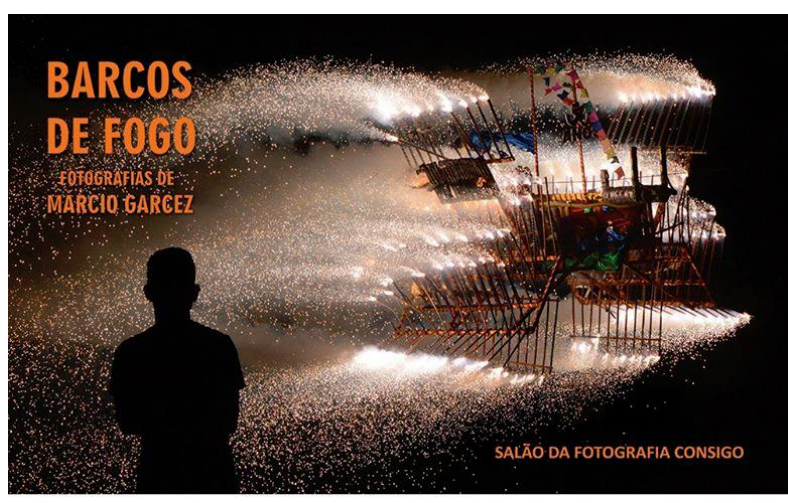

SALÃO DA FOTOGRAFIA CONSIGO 2015

BARCOS DE FOGO

FOTOGRAFIAS DE MÁRCIO GARCEZ

Curadoria
Rosana Eduardo S. Laale Vanessa Noronha Tölle
Curdodora convidoda: Moyra Xavier

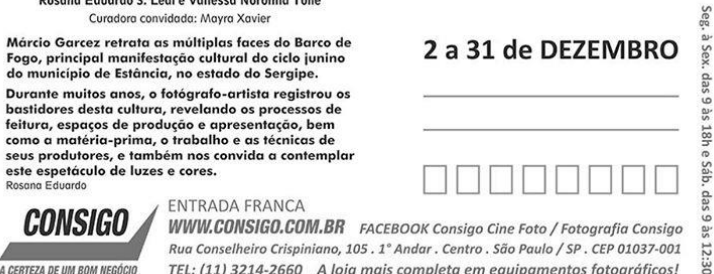

CONSIGO WWW.CONSIGO.COM.BR FACEBOOK Consigo Cine Foto / Fotografia Consigo Rua Conselheiro Crispiniano, 105. $1^{\circ}$ Andar. Centro. São Paulo/SP. CEP 01037-001
TEL - (11) 3214-2660 A loja mais completa em equipamentos fotogräficos!

Figura 05 - Convite da Exposição em São Paulo Fonte: Consigo Cine Foto

Em 2017, a exposição foi selecionada em chamada pública para compor a programação cultural do I Seminário Latino-Americano de Estudos em Cultura - SEMLACult, evento internacional realizado nos dias 28, 29 e 30 de junho em Foz do Iguaçu, nas dependências da Universidade Federal da Integração Latino-Americana - UNILA. O evento teve como tema "a Mundialização da Cultura na Globalização e os Processos Decoloniais na América-Latina" uma iniciativa do Centro Latino-Americano de Estudos em Cultura - CLAEC. A finalidade do Seminário foi propor uma programação científica e cultural capaz de refletir as diversas dimensões da cultura, considerando os processos de mundialização das identidades culturais. A mostra foi exposta no hall do auditório "Martina Piazza Conde" onde ocorreram as principais atividades acadêmico-científicas do evento. Na ocasião, o público conferiu o olhar etnográfico e artístico de Márcio Garcez diante de uma das mais importantes manifestações culturais do ciclo junino sergipano, conhecendo a cultura do fogo do município de Estância, em Sergipe. 


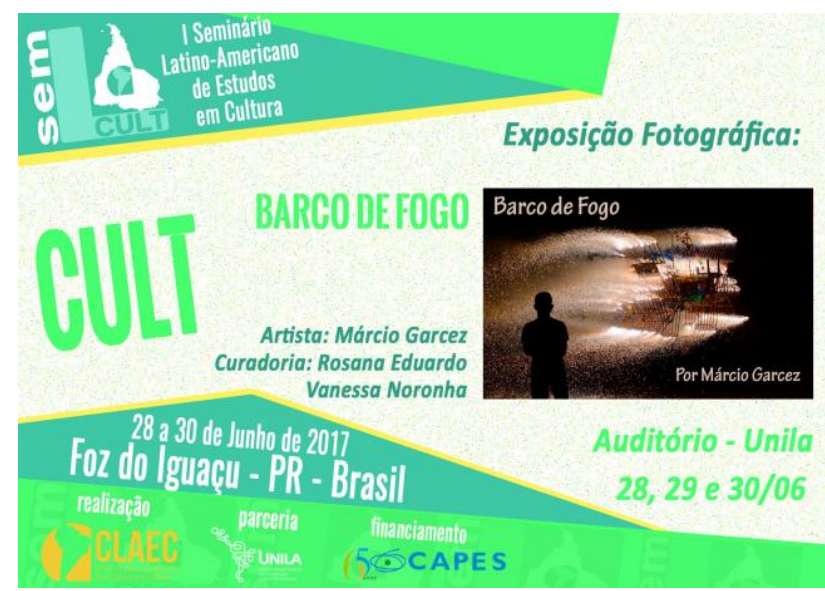

Figura 06 - Convite da Exposição em Foz do Iguaçu Fonte: CLAEC

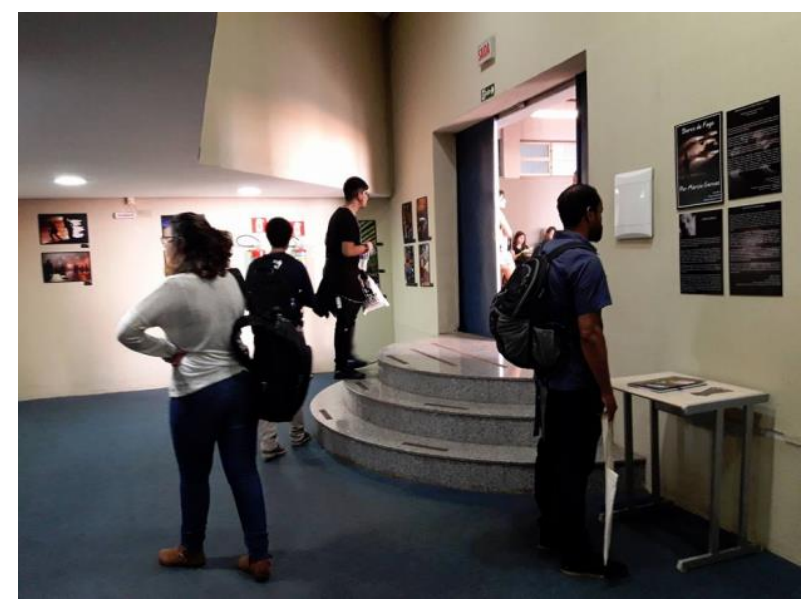

Fotografia 06 - Exposição em Foz do Iguaçu (UNILA) Fonte: acervo do projeto

Quando desenvolvidas nos espaços culturais das universidades, as exposições fotográficas promovem o diálogo entre instituição, artista, comunidade e obras, estimulando a formação do capital cultural do público visitante. Neste âmbito, podem ter implicações muito potentes, na medida em que proporcionam outras dimensões pedagógicas de encontro com o outro e a sua cultura, colocando em diálogo o popular, o científico e o artístico.

\section{Considerações Finais}

O registro fotográfico aprofunda e amplia o olhar, promove o exercício da curiosidade, descoberta e estranhamento, podendo ser utilizado por diversos campos de conhecimento, uma vez que possibilita leituras diferenciadas das habitualmente existentes. Diante do que foi apresentado, concluímos que as exposições fotográficas atuam como importantes ferramentas de difusão artística, educativa e cultural em âmbito nacional e internacional. Tais produções estão baseadas no talento e na criatividade humana e constituem importantes ferramentas da cadeia produtiva da cultura, sendo responsáveis pela ativação de diversos setores econômicos, tais como: espaços culturais, serviços gráficos, meios de hospedagem, transporte aéreo e terrestre, transportadoras, trabalhadores e serviços de alimentação. 
Quando realizadas em solo estrangeiro, as exposições fotográficas possibilitam o escoamento da produção artística brasileira, estimulando o intercâmbio, o empreendedorismo e a criação de novas parcerias, favorecendo a circulação do talento brasileiro em contexto internacional. Para o público participante, tais eventos atuam como opção de aprendizagem cultural e lazer local, promovendo as artes e o diálogo entre os povos. Para os artistas envolvidos, as exposições representam importantes momentos de encontro com outros artistas, instituições e público em geral. São ferramentas de intensa potencialidade criativa, na medida em que absorvem diversas linguagens artísticas, possibilitando a produção e o intercâmbio de produções e atividades culturais.

\section{Referências}

BONI, C.; MORESCHI, B. M.. Fotoetnografia: a importância da fotografia para o resgate etnográfico. In: Doc On-line, n.03, Dezembro 2007, pp. 137-157. Disponível em: www.doc.ubi.pt. Acesso em 20.jul.2017.

Barco de Fogo. Catalogo de la exposición fotográfica "Barco de Fogo". Residência Artística 2015. Centro de Estudios Brasileños de la Universidad de Salamanca. Salamanca: junho, 2015. Disponível em: https://issuu.com/cebusal/docs/catalogo_barco_de_fogo. Acesso em 01.jul.2017.

BRASIL. Decreto Federal, $n^{o}$ 3.551, de 04 de agosto de 2000. Institui o Registro de Bens Culturais de Natureza Imaterial que constituem patrimônio cultural brasileiro, cria o Programa Nacional do Patrimônio Imaterial e dá outras providências. Disponível em: http://www.planalto.gov.br/ccivil_03/decreto/d3551.htm. Acesso em: 02. jul. 2017.

CERQUEIRA, F. V. Patrimônio cultural, escola, cidadania e desenvolvimento sustentável. Diálogos, v. 9, n. 1, p. 91-99, 2005. Disponível em: http://www.dialogos.uem.br. Acesso em: 02. abril. 2017.

IPHAN. A fotografia na preservação do patrimônio cultural: uma abordagem preliminar. Rio de Janeiro: IPHAN, COPEDOC, 2008.

MARTINS, J. S. Sociologia da fotografia e da imagem. São Paulo: Contexto, 2013.

NOVAES, S. C., "O uso da imagem na antropologia”. In: SAMAIN, E. (org). O Fotográfico. São Paulo: Hucitec, 1998, pp.113-119.

Portal Expressão Sergipana. "Fotógrafo Sergipano Apresentou Exposição 'Barco de Fogo' em Foz do Iguaçu”. Disponível em: http://expressaosergipana.com.br/. Acesso em 15 de julho 2017.

RIBEIRO, E. T. Diplomacia Cultural: seu papel na política externa brasileira. Brasília: FUNAG, 1989. 
SILVA, P.S. Mestres do Fogo: a fabricação dos fogos de artifício em Estância-SE. In: V REUNIÃO EQUATORIAL DE ANTROPOLOGIA, XIV REUNIÃO DE ANTROPOLOGIA DO NORTE E NORDESTE - REA, ABANNE, 2015, Maceió/Alagoas. Anais Eletrônicos. Maceió: Universidade Federal de Alagoas, 2015. Disponível em: <http://www.evento.ufal.br/anaisreaabanne/>Acesso em 15 de jul.2017.

Fogo no beco que o beco está escuro!" A confecção dos fogos de artifício em Estância - SE. IN: $30^{a}$ REUNIÃO BRASILEIRA DE ANTROPOLOGIA - RBA, João Pessoa/Paraíba. Anais Eletrônicos. João Pessoa: Universidade Federal da Paraíba, 2016. Disponível em: < http://www.30rba.abant.org.br/>. Acesso em 16 de jul.2017.

SONTAG, S. Sobre a fotografia. São Paulo: Companhia das Letras, 2004.

SOUZA, M.S. O Barco de Fogo como Patrimônio Imaterial: subsídios para o registro. Disponível em: http://www.ufs.br/conteudo/2294. Acesso em 20.jul.2017. 